\title{
The Importance of Job Demands and Supports: Promoting Retention Among Child Welfare Workers
}

\author{
Melissa Radey ${ }^{1}$ (D) Dina J. Wilke ${ }^{1}$ (D) \\ Accepted: 24 April 2021 / Published online: 4 May 2021 \\ (c) The Author(s), under exclusive licence to Springer Science+Business Media, LLC, part of Springer Nature 2021
}

\begin{abstract}
Child welfare workers typically face strict deadlines, limited training periods, high caseloads, and understaffing. These highdemand positions often coupled with few organizational or supervisory supports contribute to decreased worker well-being and low retention. Informed by the Job Demands-Resources model, we examined common demand-resource sub-groups among recently-hired child welfare workers and how sub-group membership contributed to agency retention. This study used data from the Florida Study of Professionals for Safe Families (FSPSF), a four-year, longitudinal cohort study of child welfare workers hired in 2015-16 $(n=912)$. We used a three-step Latent Profile Analysis (LPA) with logistic regression to identify profiles of workers based on demand and support levels at 6 months to predict agency retention 12 months later. Findings resulted in five profiles: floundering, surviving through supervisor, surviving through role, surviving through supports, and thriving. Profile distributions indicated both demands and supports were independently important for retention. Each profile had higher odds of staying at the agency compared to the floundering profile, those floundering in role and support (ORs $=2.08-7.68)$. Those in the thriving profile, thriving in role and support, had higher odds of staying when compared to each other profile (ORs $=2.12-7.68)$. Findings identify that demands and supports operate in an additive way to promote retention and suggest that agencies can address individual aspects of workers' role and support challenges to improve retention without requiring a single approach to combat workload and environment simultaneously.
\end{abstract}

Keywords Child welfare workforce $\cdot$ Job demands $\cdot$ Workplace supports $\cdot$ Worker retention

Child welfare workers face the ambitious and critical goals of keeping children and families safe through investigating abuse and neglect allegations and working with families with substantiated child maltreatment. Strict deadlines, limited training periods, high caseload sizes, and complex caseloads coupled with understaffed agencies add to the challenging work (Edwards \& Wildeman, 2018; Schelbe et al., 2017). These high-demand positions often coupled with few organizational or supervisory supports contribute to decreased worker well-being (Lizano \& Mor Barak, 2012) and job burnout (He et al., 2018). Moreover, job conditions contribute to high rates of turnover: frontline child welfare worker turnover ranges from $20-50 \%$ in the US, with most turnover occurring within the first two years of hire (Edwards \& Wildeman, 2018; Smith, 2005). And, job retention is important

Melissa Radey

mradey@fsu.edu

1 College of Social Work, Florida State University, 296

Champions Way, Tallahassee, FL 32303-2570, USA for worker-family relationships, child safety, and child permanency (US DHHS, 2020). Given the impact of job demands and resources, particularly for workers in stressful positions, we used the Job Demands-Resources (JD-R) model (Demerouti et al., 2001) and latent profile analysis (LPA) to examine common demand-resource profiles among recently-hired child welfare workers and consider how these profiles contribute to agency retention in the first 18 months after hire.

\section{Agency Retention and the Child Welfare Workforce}

Workforce turnover is a critical issue for child welfare services and a significant amount of research has focused on personal and organizational factors that contribute to departure from child welfare (Wilke et al., 2018). Less attention has been directed toward understanding why workers remain on the job. However, different factors appear to 
predict turnover versus retention (Kim \& Kao, 2014; Wilke et al., 2018). This study examined retention because of its relevancy to job demands and resources (Bakker \& Demerouti, 2007) and worker and client wellbeing (US DHHS, 2020). Research suggests organizational culture and climate, including supervisor and peer support, along with job demands and work self-efficacy all contribute to child welfare workers' decisions to remain on the job (Sedivy et al., 2020; Zeitlin et al., 2014).

\section{Theoretical Framework: JD-R Model and Agency Retention}

The Job Demands-Resources (JD-R) model (Demerouti et al., 2001) states that work environment characteristics, including job demands, job resources, and personal resources shape work experiences and worker well-being contributing to agency retention. Job demands refer to the physical, psychological, social, or organizational dimensions of the job and, thereby, potential physical or psychological cost (Bakker \& Demerouti, 2007). The demands of child welfare work often include excessive workloads, highstakes situations, and emotionally draining responsibilities. Workers in high-demand positions require job resources to counteract demands and related stresses. Resources reduce job demands, promote organizational goals, and stimulate worker growth (Bakker \& Demerouti, 2007). Typical resources for child welfare workers include organizational characteristics (e.g., pay and advancement opportunities), work structure (e.g., how work is allocated), work tasks, and interpersonal supports (e.g., organizational, supervisory, and co-worker). In addition to job resources, personal resources, or worker characteristics that contribute to resiliency, also influence worker well-being and retention.

The JD-R model emphasizes the interplay between and among factors. The model proposes that demands and resources interact such that the importance of job demands for organizational outcomes depends on resources and vice versa. Individuals' work and personal resources can buffer the effects of job demands. In addition, separate dimensions of demands and resources may affect workers differently. For example, supervisory support may buffer role overload (i.e., too much work and pressure) while co-worker support may not. Or, perhaps, workers' coping skills help them to negotiate role overload, but not work conflict (i.e., conflicting rules and directions). LPA analysis is ideal to test the JD-R model because of the interdependency within and between job demands, job resources, and personal resources (Lee $\&$ Cho, 2020). The analysis will identify the frequency of various profiles and how unique profiles influence retention (see Fig. 1).

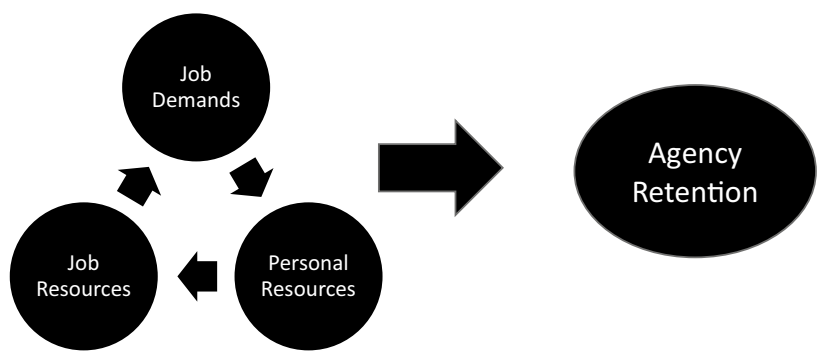

Fig. 1 Conceptual framework

\section{Job Demands and Resources in Child Welfare}

\section{Job Demands}

Extensive evidence suggests that role overload and role conflict, two components of job stress, contribute to workers' decisions about whether or not to leave their agencies (Cahalane \& Sites, 2008; Hopkins et al., 2010; Nissly et al., 2005; Travis et al., 2016). For example, child welfare workers who remained in child welfare had lower levels of role overload and role conflict than those who left (Cahalane \& Sites, 2008). Similarly, Hopkins et al. (2010) found that work stress, captured in part by role overload and role conflict, contributed to agency departure more than any other factor including personal (e.g., demographics) or job characteristics (e.g., caseload size). Kim and Kao's (2014) meta-analysis also indicated the importance of work environment and attitudes, including role overload and conflict, for child welfare workers' intentions to stay, a strong indicator of actual retention (Auerbach et al., 2014; Boyas et al., 2013).

\section{Job Resources}

Job resources in the form of supportive organizations and supervisors also contribute to workers' retention (Boyas \& Wind, 2010; Dickinson \& Perry, 2002; Kim \& Mor Barak, 2015; Smith, 2005). In a longitudinal study of child welfare workers in one state, Smith (2005) found that workers with supervisory support one standard deviation above the mean had 57\% higher odds of remaining at their agencies 15-17 months later than workers at the mean. Using Cox regression models to predict retention among a large sample of child welfare workers in Texas $(n=9,195)$, Madden et al. (2014) found that high levels of organizational support related to longer work tenures and less turnover in the first three years of the job.

While much evidence attests to the importance of supervisory and organizational support for retention, findings 
on the importance of co-worker support for retention are mixed with some studies finding co-worker support decreases intent to leave and increases retention (Chenot et al., 2009; Dickinson \& Perry, 2002; Ellett \& Millar, 2004; Nissly et al., 2005; Scannapieco \& Connell-Carrick, 2007) while others find no influence (Jacquet et al., 2008; Wilke et al., 2019). In a sample of rural and urban workers in California, those with peer support had a higher likelihood of intention to stay in the field than those with less peer support. Likewise, in a sample of recently-hired child welfare workers in Texas $(n \sim=1,100)$, co-worker (and supervisory) support contributed to enthusiasm for the job and higher levels of agency retention (Scannapieco \& Connell-Carrick, 2007). However, in a sample of child welfare workers with Master's of Social Work degrees, co-worker support was not significant in predicting intent to leave or actual departure (Jacquet et al., 2008).

\section{Personal Resources}

Relative to job demands and work resources, the role of personal resources (i.e., self-esteem, coping skills, support from family or friends) in child welfare worker retention has received little attention. However, a recent examination of the JD-R model indicates their potential importance for worker psychological well-being (Lee \& Cho, 2020), which is one of the strongest predictors of child welfare worker retention (Kim \& Kao, 2014). In the one identified study that examined self-esteem and an aspect of retention (i.e., worker turnover), it was not significant (Jayaratne et al., 1991). Likewise, Nissly et al. (2005) found that support from family or friends did not influence turnover. However, an examination of nurses, other human service professionals similar in many ways to child welfare workers, found that those with less support from family and friends experienced higher turnover rates (Tai \& Robinson, 1998). In terms of coping among child welfare workers, evidence is inconclusive with studies indicating that healthier coping skills were associated with decreased intent to leave (Lee et al., 2011), but not with actual turnover (Wilke et al., 2019). Therefore, while many studies exclude personal resources, theory and limited empirical work suggest the importance of its inclusion.

\section{Intersection of the JD-R Model}

Job demands, job resources, and personal resources are important to consider independently when examining worker retention. However, evidence also suggests the importance of their intersection. For example, in a 12-month longitudinal study of child welfare workers, an increase in job demands was associated with a decrease in organizational support, and, subsequently higher turnover intentions (Kim \& Mor Barak, 2015). In addition, Kadushin (2002) suggests the restorative power of supervisory support is contingent on worker self-esteem and Chen and Scannapieco (2010) found that strong supervisory support fosters self-esteem. Also, one study suggested that supervisory support and support from family and friends can negate the negative relationship between stress and work outcomes (Baruch-Feldman et al., 2002). The LPA analysis provides an opportunity to examine these potentially important intersections.

\section{Contribution of Individual Worker Characteristics}

In applying the JD-R model, theoretical and limited empirical evidence also indicates the importance of individual and demographic characteristics (Lin, 2000; Mor Barak et al., 2003). In terms of workplace demands and support, Mor Barak et al. (2003) examined workers in two technological companies and found that demographic characteristics impacted workers' access to resources through unequal treatment of minority groups. Workers from diverse backgrounds experienced more job stress and less workplace support compared to workers in the mainstream. Other studies indicate few differences (Boyas \& Wind, 2010; Lowe \& Schellenberg, 2001; Requena, 2003). Among child welfare workers, Boyas and Wind (2010) found that individual differences did little to affect workers' perceptions of agency resources.

\section{Study Contribution and Hypotheses}

Variable-centered approaches (e.g., structural equations modeling) suggest the value of the JD-R model in predicting retention among child welfare workers. However, these approaches may miss important interactions between and among job demands and resources which may lead to misinterpretations when applying findings to actual workers who juggle unique combinations of demands and resources in the real-work context (Lee \& Cho, 2020). We use LPA, a person-centered approach that assumes that the population contains homogenous subgroups of workers and groups' unique combinations of job demands and resources influence agency departure. Based on the JD-R model and the reviewed literature, we hypothesize:

H1 Workers form at least 2 distinct profiles based on their levels of job demands, job resources, and personal resources.

H2 Latent profiles significantly differ in their levels of job demands, job resources, and personal resources.

H3 Job demands and resources intersect creating profiles of workers with similar levels of functionality in both domains. 
H4 Few individual characteristics are related to worker profiles.

H5 Profiles are related to agency retention such that workers with manageable demands and high resources experienced higher levels of retention.

\section{Method}

\section{Study Design and Sample}

This study used data from the Florida Study of Professionals for Safe Families (FSPSF), a four-year, longitudinal cohort study of child protection services, or child welfare, workers hired in Florida from September, 2015 through December, 2016. The study's purpose was to understand work experiences and subsequent employment decisions among the child welfare workforce. All entry-level workers hired during the recruitment period were invited to participate during their mandatory trainings; $84 \%$ did so $(n=1500)$. Respondents completed bi-annual, online surveys to measure individual and organizational characteristics; worker well-being; and retention. Study retention exceeded $75 \%$ at each wave (Wilke et al., 2017). The sample includes workers who remained in their child welfare positions 6-months post baseline at Wave $2(n=1,071)$, the first wave in which we collected job characteristics data. We use individual characteristics collected at Baseline and Wave 2 and job characteristics from Wave 2 to examine agency retention at Wave 4 (18 months after hire). Listwise deletion resulted in an analytic sample of 912. Missing data analysis indicated that included workers did not differ demographically from their non-responding counterparts. All study protocol was approved by the Institutional Review Board at the authors' university.

\section{Measures}

\section{Job Demands}

We used two, 4-item role dimensions subscales-role conflict and role overload-from Parker's Organizational Psychological Climate scale to measure job demands (Parker et al., 2003). Respondents rated their level of agreement on a 5-point Likert scale (i.e., strongly disagree to strongly agree) with the amount of conflict (e.g., There are too many people telling me what to do; I am held responsible for things over which I have no control) and overload (e.g., I have more work than I could ever get done; I am constantly under too much pressure on my job) they experienced. For ease of interpretation, all items in these two subscales were reverse-coded to reflect positive concepts. As such, higher values reflect role balance rather than role overload, and role compatibility rather than role conflict.

\section{Job Resources}

We used support from three sources: the organization, supervisors, and co-workers. Similar to job demands, we measured organizational and supervisory support from two 4-item sub-scales of Parker's Organizational Psychological Climate scale (Parker et al., 2003) measured on a 5-point Likert scale ranging from strongly disagree to strongly agree. The organizational support subscale included items such as "the organization shows little concern for me" and "the organization really cares about my well-being." Examples of supervisory support items include "My supervisor is willing to listen to my problems" and "My supervisor treats his/her people with respect."

We measured co-worker support using Caplan's Social Support Index (Caplan et al., 1975). Using a four-point Likert scale from 0 (not at all) to 3 (very much), respondents answered five items about how much support they received from their co-workers. Example items asked about available support when "things get tough at work," how much co-workers are "willing to listen to your work-related problems," and "how easy is it to talk" to coworkers. For all support scales, higher values indicate greater levels of support.

\section{Personal Resources}

We utilized measures of self-esteem, family support, and task-oriented coping skills to operationalize personal resources. Respondents completed the Rosenberg Self Esteem scale, a 10-item scale using a four-point Likert scale in which respondents noted their level of agreement from strongly disagree to strongly agree (Rosenberg, 1965). Example items include, "On the whole, I am satisfied with myself" and "All and all, I am inclined to feel that I am a failure." We reverse coded negative items, and higher score values reflect higher levels of self-esteem. To measure family support, we used the Caplan's Social Support Index used for co-worker support. Instead of co-workers, the reference was family or friends. To measure coping, respondents completed a modified version of the Coping Inventory for Stressful Situations (CISS; Endler \& Parker, 1999) a 21-item, 4-point Likert scale instrument $(0=$ not at all, $3=$ very much $)$ that consider how respondents react to stressful situations. We used responses from the 7-item task-focused sub-scale (e.g., "I focus on the problem and how I can solve it" and "I work to understand the situation"). Negative items were reverse coded, and higher scores reflect greater levels of task-oriented coping. 
Respondents completed all measures at Wave 2, roughly six months into their positions, except for the self-esteem and coping measures which were measured at baseline. Both selfesteem and coping are time stable measures (e.g., Eisenbarth, 2012; Trzesniewski, et al., 2003) suggesting that measurement six months earlier poses minimal problem. Finally, to account for missing data on each scale, we utilized person mean substitution to impute scores for respondents who answered at least $50 \%$ of the scale's items. Person mean substitution is an effective strategy when working with ordinal data on scales with $50 \%$ or less missing data on individual items (Dodeen, 2003; Hawthorne \& Elliott, 2005). The steps involved included computing mean scores for each scale and multiplying by the number of items for an overall imputed sum score. Scores for respondents who answered fewer than $50 \%$ of the scales' items were left missing.

\section{Agency Retention}

At each wave, workers indicated through a dichotomous measure if they remained employed in the same child welfare agency. We measured agency retention at Wave 4 when respondents had been in their agency for approximately 18 months. Respondents were considered retained if they answered "yes" to the retention question at both Waves 3 and 4.

\section{Individual Characteristics}

We examined a range of self-reported demographic characteristics measured at Wave 1 (time-constant attributes) and Wave 2 (time-varying attributes). Respondents identified their race from the US Census categories and specified whether they were of Hispanic or Latino origin. We created four categories: Hispanic; non-Hispanic, Black; nonHispanic, White; and non-Hispanic of another race. We measured age in years calculated from birthdate to the date of the baseline survey. Respondents indicated whether they were male or female. For marital status and family status, we distinguished between respondents who were married and those who were not, and those who had minor children from those who did not. For education, respondents indicated (a) whether they exceeded the Bachelor's degree requirement for their positions and had a Master's degree or higher in any field and (b) whether their highest degree was in the field of social work. To measure work experience, respondents indicated their number of prior years of work experience in any field. We also considered whether the respondent was a child protective investigator (e.g., investigating families for alleged maltreatment) or a case manager (e.g., working with families with verified maltreatment allegations).

\section{Analytic Strategy}

The analysis consisted of assessing the validity and reliability of the job demands, job resources, and personal resources measures through a confirmatory factor analysis and Cronbach's alpha values followed by a Latent Profile Analysis (LPA). The LPA required a manual three-step approach (Nylund-Gibson \& Choi, 2018; Vermunt, 2010) to create an underlying categorical latent variable by estimating conditional means and variances of the continuous indicators.

The first step identified the best-fitting unconditional model and saved the posterior probabilities and modal class assignment. We used the Akaike Information Criterion (AIC; Akaike, 1974), Bayesian Information Criterion (BIC; Schwarz, 1978), a sample size-adjusted BIC (ABIC; Sclove, 1987), and the Lo-Mendell-Rubin adjusted likelihood ratio test (LMR LRT; Lo et al., 2001) to select the best fitting model. Models with lower AIC, BIC, ABIC values suggest better fit. LMR LRT is a Chi-squared difference test between $\mathrm{k}$ classes and $\mathrm{k}-1$ classes in which a significant result suggests $\mathrm{k}$ classes provide better fit. We compared models beginning with two profiles and concluding when consecutive models indicated worse fit. Because fit indices did not converge on one solution, typical in these analyses, we determined the final profiles through fit indices, model parsimony, and theoretical relationships based on the JD-R model (Nylund et al., 2007). In addition, we graphed the indices and considered "elbows" at which the addition of a profile improved fit more than others (NylundGibson \& Choi, 2018). We reported class entropy, a measure of overall classification into profiles, but as Vermunt and Magidson (2002) advise did not use it in model selection. Entropy approaching 0.80, as ours and other examinations of job demands and resources did (e.g., Lee \& Cho, 2020), indicates a low risk of misclassification (Vermunt, 2010). After selecting a model, we conducted Chi-Square tests and t-tests as appropriate to consider if latent profiles significantly differed by each profile indicator and workers' individual characteristics.

The second step of the 3-step LPA involved computing the estimated conditional probabilities for modal class assignment considering actual latent class membership. These probabilities provided the estimated average classification errors for modal class assignment and were treated as fixed parameter values representing the relationship between the latent profile variable and the multinomial modal class assignment to use in the next step (Nylund-Gibson et al., 2019).

The third step used the modal class assignment from step one as a single nominal indicator of the latent class variable coupled with the fixed classification error values calculated in step two to estimate a new model. The model included 
the significant individual characteristic predictors of latent profile and the unique characteristics of the latent profiles to predict the distal outcome of agency retention using logistic regression analysis. We used post-hoc tests to consider how workers in each profile differed in their odds of staying at their agencies relative to each other profile. We provide logodds and odds ratios for logistic regression results.

\section{Results}

\section{Validity and Reliability of Scales Measuring Job Demands and Resources}

Before conducting the LPA, we examined the reliability and validity of the job demands and resources measures. Following others (e.g., Lee \& Cho, 2020), we conducted a confirmatory factor analysis (CFA) and all factors met the factor loading criterion of 0.50 or more. Cronbach's alpha scores demonstrated reliability ( $\alpha=0.68-0.90)$, with only role conflict slightly below the traditional 0.70 cutoff. Because role conflict approached the traditional cutoff of 0.70 and met acceptance when coupled with role overload $(\alpha=0.84)$, we included the measure. Table 1 presents scale reliabilities, correlations, and tests of significance with Bonferroni correction for all scales.

\section{Latent Profile Analysis}

To identify the best-fitting model, we tested fit statistics for models with two through eight profiles (see Table 2). The AIC, BIC, and ABIC decreased with the addition of each factor. The $p$ value of the LRT varied over time with two consecutive non-significant tests in models with seven and eight profiles. The graph of the indices indicated significant improvement ("elbows") at three and five profiles. Based upon the combination of fit indices, degree of incremental improvement, profile distinctness, and theoretical
Table 2 Fit indices for latent profile models $(n=912)$

\begin{tabular}{llllll}
\hline Model & AIC & BIC & A-BIC & Entropy & LRT \\
\hline 2 Profile & $19,400.72$ & $19,521.11$ & $19,441.72$ & 0.70 & $p<.001$ \\
3 Profile & $19,095.86$ & $19,259.59$ & $19,151.61$ & 0.76 & $p<.001$ \\
4 Profile & $18,991.52$ & $19,198.59$ & $19,062.03$ & 0.69 & $p=.35$ \\
5 Profile & $19,062.03$ & $19,086.16$ & $19,086.16$ & 0.75 & $p=.03$ \\
6 Profile & $19,086.16$ & $19,044.31$ & $18,850.58$ & 0.75 & $p=.02$ \\
7 Profile & $18,699.27$ & $18,699.27$ & $18,699.27$ & 0.77 & $p=.31$ \\
8 profile & $18,660.17$ & $18,660.17$ & $18,789.71$ & 0.73 & $p=.45$ \\
\hline
\end{tabular}

relationships proposed in the JD-R model, we selected the 5-profile model.

Figure 2 displays the distribution of criteria variables for each latent profile. For comparison purposes, variables were standardized. Positive scores indicate that the profile mean was higher than the overall sample mean while negative scores indicate the profile mean score was lower than the sample mean. All scales were coded such that higher levels denote more desirable characteristics (e.g., more balance, more support). We labeled the largest profile surviving through support (Profile 4 and 35\% of all workers). Members of this profile averaged slightly above and below the mean for role balance and role compatibility, respectively, while they averaged more organizational, supervisory, and co-worker support resources than the overall mean. The next largest profiles were labeled surviving through supervision (Profile 2) and surviving through role (Profile 3). Members of the surviving through supervision profile had mostly negative experiences across all scales, with supervisory support being the exception where members averaged above the mean. Those in the surviving through role profile were slightly above the average on both role balance and role compatibility, but had less support, particularly from their supervisors. Although some workers in all profiles left their agencies, we termed the "surviving" groups to highlight the positive elements
Table 1 Reliabilities and correlations for study variables $(\mathrm{n}=912)$

\begin{tabular}{lllllllll}
\hline & $(1)$ & $(2)$ & $(3)$ & $(4)$ & $(5)$ & $(6)$ & (7) & $(8)$ \\
\hline 1. Role Overload & .88 & & & & & & & \\
2. Role Conflict & $0.56^{* *}$ & .68 & & & & & & \\
3. Organizational Support & $0.48^{* *}$ & $0.55^{* *}$ & .84 & & & & & \\
4. Supervisor Support & $0.21^{* *}$ & $0.31^{* *}$ & $0.54^{* *}$ & .87 & & & & \\
5. Co-worker Support & $0.17^{* *}$ & $0.25^{* *}$ & $0.36^{* *}$ & $0.33^{* *}$ & .90 & & & \\
6. Self-esteem & $0.17^{* *}$ & $0.17^{* *}$ & 0.09 & 0.07 & $0.11^{*}$ & .88 & & \\
7. Family Support & $0.19^{* *}$ & $0.22^{* *}$ & $0.25^{* *}$ & $0.16^{* *}$ & $0.39^{* *}$ & $0.22^{* *}$ & .81 & \\
8. Coping skills & 0.05 & 0.02 & 0.081 & 0.07 & 0.10 & $0.24^{* *}$ & $0.16^{* *}$ & .89 \\
M & 5.15 & 7.67 & 8.21 & 11.18 & 10.18 & 24.41 & 10.23 & 13.94 \\
SD & 3.71 & 3.16 & 3.84 & 3.96 & 3.60 & 4.74 & 3.44 & 4.46 \\
\hline
\end{tabular}

$* * \mathrm{p}<.01$ 


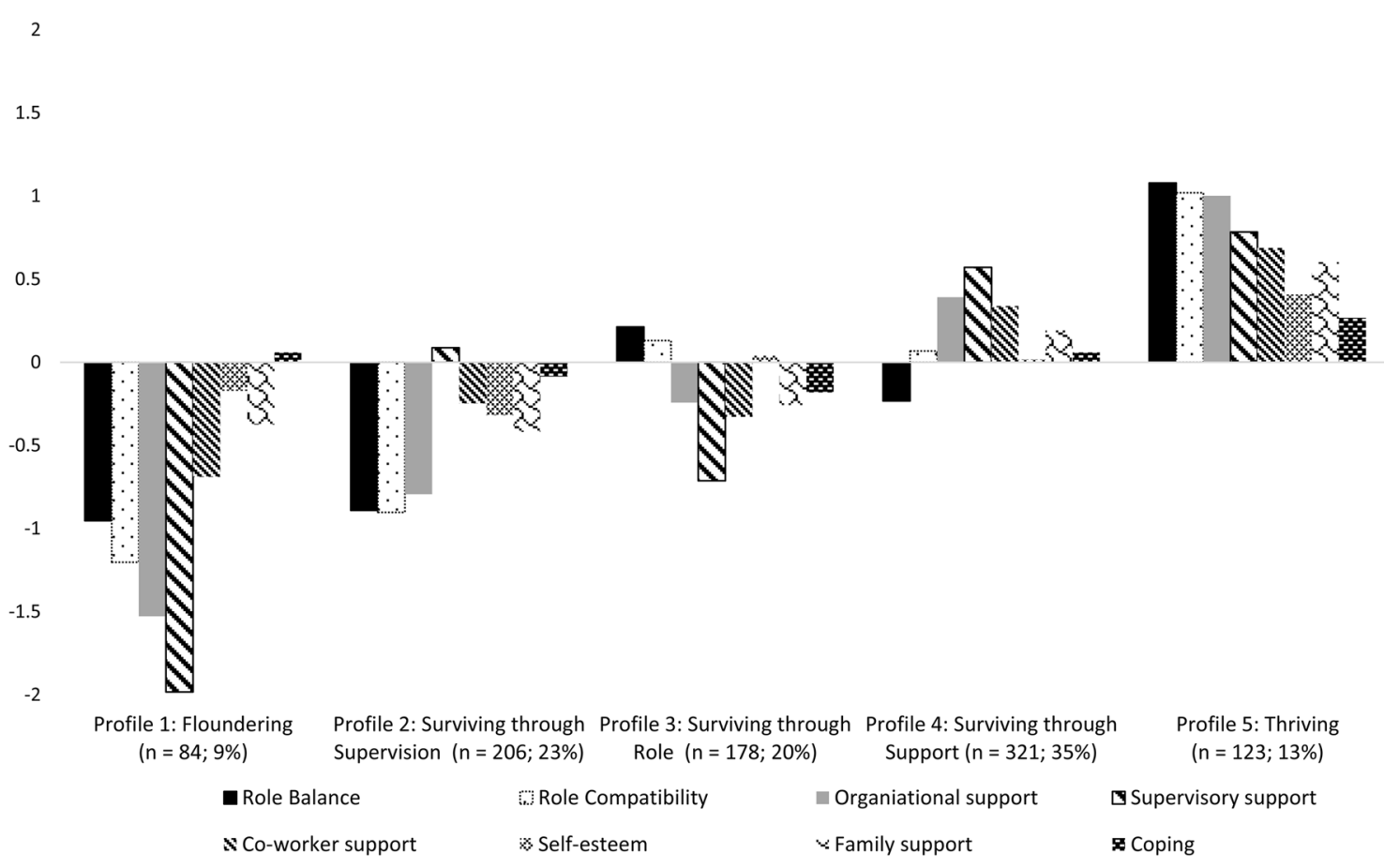

Fig. 2 Distribution of criteria variables for each latent profile

Table 3 Within profile unstandardized means, standard deviations, and significant differences between profiles by variable

\begin{tabular}{|c|c|c|c|c|c|c|c|}
\hline & $\begin{array}{l}\text { Profile 1: Floun- } \\
\text { dering }\end{array}$ & $\begin{array}{l}\text { Profile 2: Sur- } \\
\text { viving through } \\
\text { Supervisor }\end{array}$ & $\begin{array}{l}\text { Profile 3: Sur- } \\
\text { viving through } \\
\text { Role }\end{array}$ & $\begin{array}{l}\text { Profile 4: Sur- } \\
\text { viving through } \\
\text { Support }\end{array}$ & $\begin{array}{l}\text { Profile 5: Thriv- } \\
\text { ing }\end{array}$ & $\begin{array}{l}\text { Significant Dif- } \\
\text { ferences }(\mathrm{p}<.05)\end{array}$ & $\begin{array}{l}\text { Theoretical } \\
\text { Scale Range }\end{array}$ \\
\hline Role balance & $1.89(2.28)$ & $2.08(2.13)$ & $6.96(2.47)$ & $4.83(2.57)$ & $10.73(2.48)$ & $\begin{array}{l}1<3,4,5 \\
2<3,4,5 \\
3>4 ; 3<5 \\
2<4 ; 4<5\end{array}$ & $0-16$ \\
\hline $\begin{array}{l}\text { Role compat- } \\
\text { ibility }\end{array}$ & $3.96(2.35)$ & $4.90(2.10)$ & $8.62(1.80)$ & $8.36(2.26)$ & $11.65(2.10)$ & $\begin{array}{l}1<2,3,4,5 \\
\quad 2<3,4,5 ; 3<5 \\
4<5\end{array}$ & $0-16$ \\
\hline $\begin{array}{l}\text { Organizational } \\
\text { support }\end{array}$ & $2.57(2.42)$ & $5.32(2.71)$ & $7.62(1.98)$ & $10.20(2.45)$ & $12.57(2.47)$ & $\begin{array}{l}1<2,3,4,5 \\
2<3,4,5 \\
3<4,5 ; 4<5\end{array}$ & $0-16$ \\
\hline $\begin{array}{l}\text { Supervisor sup- } \\
\text { port }\end{array}$ & $3.33(2.50)$ & $11.54(2.26)$ & 7.97 (2.39) & $13.59(1.82)$ & $14.30(2.12)$ & $\begin{array}{l}1<2,3,4,5 ; 2>3 \\
2<4,5 ; 3<4,5 \\
4<5\end{array}$ & $0-16$ \\
\hline $\begin{array}{l}\text { Co-worker sup- } \\
\text { port }\end{array}$ & $7.44(3.84)$ & $9.03(3.31)$ & $8.90(3.48)$ & $11.41(2.97)$ & $12.66(2.74)$ & $\begin{array}{l}1<2,3,4,5 \\
\quad 2<4,5 ; 3<4,5 \\
\quad 4<5\end{array}$ & $0-15$ \\
\hline Family support & $9.03(4.00)$ & $8.87(3.17)$ & $9.39(3.61)$ & $11.01(2.88)$ & $12.54(2.81)$ & $\begin{array}{c}1<4,5 ; 2<4,5 ; \\
3<4,5 ; 4<5\end{array}$ & $0-15$ \\
\hline Self esteem & $23.71(5.42)$ & $22.95(4.87)$ & $24.78(4.45)$ & $24.48(4.61)$ & $26.60(3.83)$ & $\begin{array}{c}1<3,5 ; 2<3,4,5 \\
3<5 ; 4<5\end{array}$ & $0-30$ \\
\hline Coping & $14.21(3.78)$ & $13.51(4.32)$ & $13.13(4.59)$ & $14.20(4.48)$ & $14.95(4.65)$ & $\begin{array}{c}1>3 ; 2<4,5 \\
3<4,5\end{array}$ & $0-21$ \\
\hline$N$ & 84 & 206 & 178 & 321 & 123 & & \\
\hline
\end{tabular}


in their job role or support. The remaining two profiles, floundering (Profile 1) and thriving (Profile 5) reported abundantly negative or positive experiences in role balance and role compatibility and in support. Although personal resources were consistently higher in the thriving profile than in other profiles, work characteristics had a greater impact in defining profiles than personal resources.

Latent profiles indicated a wide range of demands and supports and profiles significantly differed across most profile indicators (see Table 3). Pairwise comparisons indicated that all groups differed from each other on role balance, except for the comparison between Floundering and Surviving through Supervision. All profiles except surviving through role and surviving through support differed from one another on role compatibility. Profiles followed a similar pattern in terms of workplace support with profiles differing from each other with few exceptions. Personal resources, alternatively, showed fewer differences. Although most profiles had fewer personal resources than the thriving profile, the surviving profiles-those containing the most members-had few differences in personal resources.

Table 4 Demographic characteristics and agency retention by profile

\begin{tabular}{|c|c|c|c|c|c|c|}
\hline & Full Sample & $\begin{array}{l}\text { Profile } 1 \\
\text { Floundering } \\
(9 \%)\end{array}$ & $\begin{array}{l}\text { Profile } 2 \text { Surviving } \\
\text { through Supervisor } \\
(23 \%)\end{array}$ & $\begin{array}{l}\text { Profile } 3 \text { Surviving } \\
\text { through Role }(20 \%)\end{array}$ & $\begin{array}{l}\text { Profile } 4 \text { Surviving } \\
\text { through Support } \\
(35 \%)\end{array}$ & $\begin{array}{l}\text { Profile } 5 \\
\text { Thriving } \\
(13 \%)\end{array}$ \\
\hline $\begin{array}{l}\text { Agency retention: Yes at } 18 \\
\text { months }^{\mathrm{a}}\end{array}$ & 54.8 & 31.0 & 47.1 & 58.4 & 57.0 & 73.2 \\
\hline \multicolumn{7}{|l|}{ Race and Ethnicity } \\
\hline Black & 31.5 & 28.6 & 28.4 & 40.5 & 29.0 & 32.5 \\
\hline Hispanic & 17.4 & 14.3 & 16.2 & 19.1 & 18.1 & 17.1 \\
\hline White & 47.4 & 53.6 & 50.5 & 36.5 & 48.9 & 50.0 \\
\hline Other, Non- Hispanic & 3.7 & 3.6 & 4.9 & 3.9 & 4.1 & 0.8 \\
\hline \multicolumn{7}{|l|}{$\mathrm{Age}^{\mathrm{b}}$} \\
\hline $20-29$ & 57.2 & 50.0 & 60.2 & 60.7 & 58.3 & 49.6 \\
\hline $30-39$ & 25.0 & 21.4 & 25.2 & 26.4 & 24.9 & 25.2 \\
\hline $40+$ & 17.8 & 28.6 & 14.6 & 12.9 & 16.8 & 25.2 \\
\hline \multicolumn{7}{|l|}{ Married } \\
\hline Yes & 31.3 & & & & & \\
\hline No & 68.7 & & & & & \\
\hline \multicolumn{7}{|l|}{ Gender } \\
\hline Female & 85.7 & 85.7 & 87.9 & 87.0 & 84.4 & 83.7 \\
\hline Male & 14.3 & 14.3 & 12.1 & 13.0 & 15.6 & 16.3 \\
\hline \multicolumn{7}{|l|}{ Has master's degree +} \\
\hline Yes & 18.9 & 16.9 & 21.4 & 14.0 & 18.1 & 25.2 \\
\hline No & 81.1 & 83.1 & 78.6 & 86.0 & 81.9 & 74.8 \\
\hline \multicolumn{7}{|c|}{$\begin{array}{l}\text { Has social work degree as high- } \\
\text { est degree }\end{array}$} \\
\hline Yes & 18.8 & 19.1 & 19.9 & 21.3 & 19.7 & 10.6 \\
\hline No & 81.2 & 81.0 & 80.1 & 78.7 & 80.3 & 89.4 \\
\hline \multicolumn{7}{|l|}{ Parent of minor child } \\
\hline Yes & 25.9 & 30.9 & 27.0 & 21.8 & 24.8 & 29.7 \\
\hline No & 74.1 & 69.1 & 73.0 & 78.2 & 75.2 & 70.3 \\
\hline Years of work experience & 8.4 & 10.3 & 7.8 & 7.6 & 8.0 & 10.0 \\
\hline \multicolumn{7}{|l|}{$\begin{array}{l}\text { Child protective investigator } \\
\text { (CPI) }\end{array}$} \\
\hline Yes & 43.5 & 42.9 & 40.8 & 38.8 & 45.5 & 50.4 \\
\hline No & 56.5 & 57.1 & 59.2 & 61.2 & 54.5 & 49.6 \\
\hline$N$ & 912 & 84 & 206 & 178 & 321 & 123 \\
\hline
\end{tabular}

${ }^{a}$ All profiles differed from each other except for those surviving by role and those surviving by support. $(p<.05)$

${ }^{\mathrm{b}}$ Floundering and Thriving profiles had fewer workers in their $20 \mathrm{~s}$ compared to other profiles. $(p<.05)$

${ }^{\mathrm{c}}$ Floundering and Thriving profiles had a higher mean of prior years of work experience compared to other profiles. $(p<.05)$ 
We next examined how individual characteristics and agency retention related to profile membership (see Table 4). Only age and years of work experience significantly related to profile. Workers 40 years and older and those with more years of work experience were disproportionately represented in the extreme classes (i.e., floundering or thriving). Examining agency retention, slightly over one-half of workers remained at the agency 12 months later. Profile membership was strongly associated with retention such that all profiles were statistically different from each other with the exception of those surviving through role and those surviving through support. At the extremes, only $31 \%$ of floundering workers remained 12 months later compared to $73 \%$ of thriving workers.

In the third step of the LPA, we used modal class assignments and fixed classification error values in a multinomial regression model estimating the effect of work experience on profile membership followed by a logistic regression to estimate agency retention 12 months later. Because age and years of work experience were strongly correlated $(\rho>0.8)$, we excluded age in the three-step regression. Reflective of the descriptive results, for each year of work experience, respondents had a 3-4\% lower odds of being in one of the surviving profiles relative to both the floundering and thriving profiles. Years of work experience did not significantly differ between those in the floundering or thriving profiles.

In terms of the effect of profile differences on agency retention, we used post-hoc tests from the logistic regression analysis to compare the odds of staying at the agency at 18 months post-hire between each set of profiles (See Table 5). Each profile had higher odds of staying at the agency when compared to the floundering profile $(\mathrm{ORs}=2.08-7.68)$. At the other extreme, those in the thriving profile had higher odds of staying when compared to each other profile $(\mathrm{ORs}=2.12-7.68)$. Those who were surviving through supervision had $43 \%$ lower odds of staying relative to those who were surviving through role.

\section{Discussion}

Research has demonstrated the importance of manageable job demands and supportive work environments for agency retention among child welfare workers (Edwards \& Wildeman, 2018). Although the JD-R model (Demerouti et al., 2001) and empirical work in other professions (e.g., Lee \& Cho, 2020) demonstrate their importance, to our knowledge no studies have examined common profiles of job demands and job resources for child welfare workers and how these profiles contribute to worker retention. This gap in knowledge is notable because retention promotes both worker and client well-being (Boyas et al., 2013; US DHHS, 2020). With a statewide, cohort sample of child welfare workers hired in 2015-16, this study uncovered distinguishable profiles of job demands (i.e., role overload, role conflict) and job resources (i.e., organization, supervisor, and co-worker) at six months post hire and their importance for agency retention 12 months later. Findings contribute two central findings to the literature: (a) rather than a dichotomy of worker experiences (e.g., good/bad), workers experienced a variety of job demand and resource configurations, and (b) profiles related to agency retention such that both job demands and job resources are independently important for retention.

\section{Worker Job Demand and Resources Profiles}

Congruent with our first hypothesis, results supported five profiles: floundering, surviving through supervision, surviving through role, surviving through support, and thriving. With the exception of workers in the surviving by supervision profile who averaged below the sample mean on all measures except supervisory support, workers' supervisory, organizational, and co-worker resources were uniformly above or below average suggesting each type of resource's importance in shaping workers' experiences. Counter to Lee and Cho's (2020) findings examining older workers across

Table 5 Logistic regression results for retention by the latent profiles

\begin{tabular}{|c|c|c|c|c|c|}
\hline & Log-Odds & Confidence interval & Standard Error & Odds ratio & $\mathrm{p}$ value \\
\hline Surviving through role vs. Floundering & 1.286 & $(0.724-1.849)$ & 0.342 & 3.618 & 0.000 \\
\hline Surviving through supervision vs. Floundering & 0.732 & $(0.173-1.290)$ & 0.339 & 2.079 & 0.031 \\
\hline Surviving through support vs. Floundering & 1.147 & $(0.638-1.657)$ & 0.310 & 3.149 & 0.000 \\
\hline Thriving vs. Floundering & 2.038 & $(1.414-2.662)$ & 0.379 & 7.675 & 0.000 \\
\hline Surviving through supervision vs. Surviving through support & 0.416 & $(0.019-0.813)$ & 0.241 & 1.042 & 0.085 \\
\hline Surviving through supervision vs. Thriving & 1.307 & $(0.799-1.814)$ & 0.309 & 3.695 & 0.000 \\
\hline Surviving through role vs. Surviving through support & -0.139 & $(-0.555-0.277)$ & 0.253 & 0.870 & 0.583 \\
\hline Surviving through role vs. Thriving & 0.752 & $(0.223-1.281)$ & 0.322 & 2.121 & 0.019 \\
\hline Surviving through support vs. Thriving & 0.891 & $(0.364-1.418)$ & 0.320 & 2.438 & 0.005 \\
\hline Surviving through supervision vs. Surviving through role & -0.555 & $(-0.996-0.113)$ & 0.268 & 0.574 & 0.039 \\
\hline
\end{tabular}


sectors, personal resources did not define any profile. For recently-hired child welfare workers, job demands and resources seem to define job experiences more than personal resources. Future work can complement the current study by examining if personal resources become more important as time passes or if other dimensions of personal support, such as self-care strategies (Griffiths \& Royse, 2017), matter.

For the most part, workers in separate profiles significantly differed in their levels of job demands and resources following our second hypothesis. Yet, counter to Hypothesis 3, findings did not indicate critical intersections of the JD-R model as suggested in earlier work (Kim \& Mor Barak, 2015). Although job demands and resources had consistent patterns among floundering and thriving profiles, profiles contained nuance beyond manageable job demands and work resources as illustrated in the surviving profiles who reported mixed work experiences.

Workers' levels of job demands and resources yielded multiple profiles without a single profile containing the majority of workers. The largest profile of workers (35\%) was surviving through support and an additional $13 \%$ were thriving — also averaging high levels of support—indicating almost one-half of workers perceived supportive workplaces. Conversely, over $25 \%$ of workers reported unmanageable demands (e.g., below average role balance and compatibility) and few resources, with 9\% of workers "floundering." Complementing earlier LCA findings using the JD-R model among older workers (Lee \& Cho, 2020), the profiles demonstrate the wide array of job demand and resource configurations child welfare workers experience with somewhat independent demand and resource levels. Supporting studies examining workplace support (Barth et al., 2008; Radey \& Stanley, 2018), about one in two workers felt supported by supervisors and organizations.

Following earlier findings (Boyas \& Wind, 2010) and Hypothesis 4, individual characteristics, with the exception of years of work experience, were not significantly related to profile. The finding that workers in the floundering and thriving profiles averaged more years of work experience than those in other profiles was unexpected. Perhaps, more experienced workers have clearer workplace expectations and whether or not their expectations are met translate into membership into a more extreme profile. Examining job demands and resources in light of expectations is important for future work. Also, job role was not significantly related to profile suggesting that job demands and resources are not inherently different for child protective investigators and case managers.

\section{Importance of Profiles for Retention}

Supporting Hypothesis 5 and previous work (Madden et al., 2014; Smith, 2005), workers' demand and resource profiles at six months into their positions were predictive of agency retention at 18 months. Most profiles differed from all others in the expected direction: workers with manageable demands and more resources had higher odds of retention. The effects of demands and resources seem to be additive-the fewer demands and more resources, the lower the odds of agency departure across resource and demand levels - rather than a set threshold of protection from agency departure. In addition, the only profiles that did not statistically differ were surviving through role and surviving through support profiles suggesting that neither job demands nor job resources are clearly more influential in child welfare workers' retention decisions. Supporting earlier studies (e.g., Boyas \& Wind, 2010; Hopkins et al., 2010), both job demand and resource levels provide protection from departure. For example, surviving through supervision profile workers' higher odds of retention compared to the floundering profile are likely attributable to their supervisory support while others survived through role or multiple agency supports, including supervision. Both manageable demands and supportive workplaces leading to "thriving" workers with significantly higher odds of retention than all other groups.

In addition to few individual differences, profiles also varied little by personal resources. These results are encouraging because the characteristics that were associated with profile and, then, retention (e.g., job demands and job resources) can be modified at the organizational level, whereas personal resources or traits are less malleable. And, previous longitudinal examinations suggest that people can and do change profiles over time (Tuominen-Soini \& Salmela-Aro, 2014). The wide range of demands and resources suggests that the work itself does not preclude manageable demands and supportive work environments.

\section{Limitations and Future Directions}

The study should be considered in light of its strengths and limitations. First, we measured job demands and resources through worker self-report at a single timepoint introducing the potential for common method bias in which the relations among the constructs may be overstated. However, the study used longitudinal data from a statewide, cohort sample of recently-hired child welfare workers increasing data quality and generalizability. Future work could test demand and support relations using data from multiple sources and examining profiles over time. Second, this is the first study to our knowledge to apply the JD-R model using LPA to understand agency retention. Future work can measure additional aspects of job demands (e.g., time pressure, role ambiguity) and supports (e.g., administrative) to increase understanding about the operation of demands and supports among child welfare workers. Third, we measured some of 
the personal resources in a global context rather than in the context of work. Although organizational-specific measures (e.g., organizational self-esteem) are likely closely related to global ones, the concepts are distinguishable. Future work could benefit for examining personal resources within an organizational context. Fourth, we did not examine the potential pathways through which demands and supports relate to retention. Substantial evidence suggests that high agency retention promotes worker morale and client outcomes (US DHHS, 2020). Knowledge about the mechanisms through which demands and supports relate to outcomes (e.g., burnout, compassion fatigue) could help agencies target interventions to increase retention.

\section{Implications}

A central goal of this study was to understand job demand and resource arrangements among recently-hired child welfare workers and how such arrangements contributed to agency retention 12 months later. Worker profiles with distinct levels of demands and resources indicate that the nature of child welfare work does not preclude role balance, role compatibility, or supportive work environments. Echoing similar findings of workers in other sectors (Lee \& Cho, 2020), two profiles, including almost one-half of workers, perceived manageable job demands and available support. This finding is refreshing because demands and supports related to worker retention: workers in the thriving profile had 7.6 higher odds of retention compared to the floundering profile. Demands and resources are influential and malleable. The profiles of workers who survived through supervision, role, or support indicate that agencies can impact workers' retention through any or all mechanisms. However, for the one half of workers in profiles without manageable demands or support resources, continued agency efforts to reduce job stress, clarify job expectations, and encourage a supportive environment could improve retention. Findings suggest that agency efforts can address individual aspects of workers' role and support challenges to improve retention without requiring a single approach to combat workload and environment simultaneously.

\section{Declaration}

Conflict of interest We have no known conflict of interest to disclose. The research was supported in part by the Florida Institute for Child Welfare.

\section{References}

Akaike, H. (1974). A new look at the statistical model identification. IEEE Transactions on Automatic Control, 19, 716-723

Auerbach, C., Schudrich, W. Z., Lawrence, C. K., Claiborne, N., \& McGowan, B. G. (2014). Predicting turnover: Validating the intent to leave child welfare scale. Research on Social Work Practice, 24, 349-355. https://doi.org/10.1177/1049731513494021

Bakker, A. B., \& Demerouti, E. (2007). The job demands-resources model: State of the art. Journal of Managerial Psychology, 22, 309-328. https://doi.org/10.1108/02683940710733115

Barth, R. P., Lloyd, E. C., Christ, S. L., Chapman, M. V., \& Dickinson, N. S. (2008). Child welfare worker characteristics and job satisfaction: A national study. Social Work, 53, 199-209

Baruch-Feldman, C., Brondolo, E., Ben-Dayan, D., \& Schwartz, J. (2002). Sources of social support and burnout, job satisfaction, and productivity. Journal of Occupational Health Psychology, 7, 84-93

Boyas, J., \& Wind, L. H. (2010). Employment-based social capital, job stress, and employee burnout: A public child welfare employee structural model. Children and Youth Services Review, 32, 380-388

Boyas, J. F., Wind, L. H., \& Ruiz, E. (2013). Organizational tenure among child welfare workers, burnout, stress, and intent to leave: Does employment-based social capital make a difference? Children and Youth Services Review, 35, 1657-1669

Cahalane, H., \& Sites, E. W. (2008). The climate of child welfare employee retention. Child Welfare, 87, 92-114

Caplan, R. D., Cobb, S., French, J. R., Harrison, R. V., \& Pinneau, S. R. (1975). Job demands and worker health: Main effects and occupational differences [Monograph]. US Department of Health, Education, and Welfare.

Chen, S. Y., \& Scannapieco, M. (2010). The influence of job satisfaction on child welfare worker's desire to stay: An examination of the interaction effect of self-efficacy and supportive supervision. Children and Youth Services Review, 32, 482-486

Chenot, D., Benton, A. D., \& Kim, H. (2009). The influence of supervisor support, peer support, and organizational culture among early career social workers in child welfare services. Child Welfare, $88,129-147$

Demerouti, E., Bakker, A. B., Nachreiner, F., \& Schaufeli, W. B. (2001). The job demands-resources model of burnout. Journal of Applied Psychology, 86, 499-512

Dickinson, N. S., \& Perry, R. E. (2002). Factors influencing the retention of specially educated public child welfare workers. Journal of Health \& Social Policy, 15(3-4), 89-103

Dodeen, H. M. (2003). Effectiveness of valid mean substitution in treating missing data in attitude assessment. Assessment \& Evaluation in Higher Education, 28, 505-513

Edwards, F., \& Wildeman, C. (2018). Characteristics of the front-line child welfare workforce. Children and Youth Services Review, 89, $13-26$

Eisenbarth, C. (2012). Coping profiles and psychological distress: A cluster analysis. North American Journal of Psychology, 14(3), $1-6$

Ellett, A. J., \& Millar, K. I. (2004). Professional organizational culture and retention in child welfare. Professional Development: The International Journal of Continuing Social Work Education, 7(3), 30-38

Endler, N. S., \& Parker, J. D. A. (1999). Coping Inventory for Stressful Situations (CISS): Manual (Revised Edition). Multi Health Systems.

Griffiths, A., \& Royse, D. (2017). Unheard voices: Why former child welfare workers left their positions. Journal of Public Child Welfare, $11,73-90$ 
Hawthorne, G., \& Elliott, P. (2005). Imputing cross-sectional missing data: Comparison of common techniques. Australian \& New Zealand Journal of Psychiatry, 39, 583-590

He, A. S., Phillips, J. D., Lizano, E. L., Rienks, S., \& Leake, R. (2018). Examining internal and external job resources in child welfare: Protecting against caseworker burnout. Child Abuse \& Neglect, $81,48-59$

Hopkins, K. M., Cohen-Callow, A., Kim, H. J., \& Hwang, J. (2010). Beyond intent to leave: Using multiple outcome measures for assessing turnover in child welfare. Children and Youth Services Review, 32, 1380-1387

Jacquet, S. E., Clark, S. J., Morazes, J. L., \& Withers, R. (2008). The role of supervision in the retention of public child welfare workers. Journal of Public Child Welfare, 1(3), 27-54

Jayaratne, S., Himle, D. P., \& Chess, W. A. (1991). Job satisfaction and burnout: Is there a difference? Journal of Applied Social Sciences, 15, 245-262

Kadushin, A. (2002). Supervision in social work (4th ed.). Columbia University Press.

Kim, H., \& Kao, D. (2014). A meta-analysis of turnover intention predictors among US child welfare workers. Children and Youth Services Review, 47, 214-223

Kim, A., \& Mor Barak, M. E. (2015). The mediating roles of leadermember exchange and perceived organizational support in the role stress-turnover intention relationship among child welfare workers: A longitudinal analysis. Children and Youth Services Review, 52, 135-143

Lee, J., Forster, M., \& Rehner, T. (2011). The retention of public child welfare workers: The roles of professional organizational culture and coping strategies. Children and Youth Services Review, 33, 102-109

Lee, Y., \& Cho, D. (2020). The effects of job demands, job resources, and personal resources on the psychological well-being of middleaged workers in the United States: Assessing latent profile differences. International Journal for Educational and Vocational Guidance, 20, 501-521

Lin, N. (2000). Inequality in social capital. Contemporary Sociology, 29, 785-795

Lizano, E. L., \& Mor Barak, M. E. (2012). Workplace demands and resources as antecedents of job burnout among public child welfare workers: A longitudinal study. Children and Youth Services Review, 34, 1769-1776

Lo, Y., Mendell, N. R., \& Rubin, D. B. (2001). Testing the number of components in a normal mixture. Biometrika, 88, 767-778

Lowe, G., \& Schellenberg, G. (2001). What's a good job? Canadian Policy Research Networks Renouf Publishing.

Madden, E. E., Scannapieco, M., \& Painter, K. (2014). An examination of retention and length of employment among public child welfare workers. Children and Youth Services Review, 41, 37-44

Mor Barak, M. E., Findler, L., \& Wind, L. H. (2003). Cross-cultural aspects of diversity and well-being in the workplace: An international perspective. Journal of Social Work Research and Evaluation, 4, 145-169

Nissly, J., Mor Barak, M., \& Levin, A. (2005). Stress, social support, and workers' intentions to leave their jobs in public child welfare. Administration in Social Work, 29, 79-100

Nylund, K. L., Asparouhov, T., \& Muthén, B. O. (2007). Deciding on the number of classes in latent class analysis and growth mixture modeling: A Monte Carlo simulation study. Structural Equation Modeling: A Multidisciplinary Journal, 14, 535-569

Nylund-Gibson, K., \& Choi, A. Y. (2018). Ten frequently asked questions about latent class analysis. Translational Issues in Psychological Science, 4, 440-461

Nylund-Gibson, K., Grimm, R. P., \& Masyn, K. E. (2019). Prediction from latent classes: A demonstration of different approaches to include distal outcomes in mixture models. Structural Equation Modeling: A Multidisciplinary Journal, 26, 967-985

Parker, C., Baltes, B. B., Young, S. A., Huff, J. W., Altmann, R. A., Lacost, H. A., \& Roberts, J. E. (2003). Relationships between psychological climate perceptions and work outcomes: a metaanalytic review. Journal of Organizational Behavior, 24, 389-416

Radey, M., \& Stanley, L. (2018). "Hands on" versus "empty”: Supervision experiences of frontline child welfare workers. Children and Youth Services Review, 91, 128-136

Requena, F. (2003). Social capital, satisfaction and quality of life in the workplace. Social Indicators Research, 61, 331-360

Rosenberg, M. (1965). Society and the adolescent self-image. Vol. 11. Princeton University Press.

Scannapieco, M., \& Connell-Carrick, K. (2007). Child welfare workplace: The state of the workforce and strategies to improve retention. Child Welfare, 86, 31-52

Schelbe, L., Radey, M., \& Panisch, L. S. (2017). Satisfactions and stressors experienced by recently-hired frontline child welfare workers. Children and Youth Services Review, 78, 56-63

Schwarz, G. (1978). Estimating the dimension of a model. The Annals of Statistics, 6, 461-464

Sclove, S. L. (1987). Application of model-selection criteria to some problems in multivariate analysis. Psychometrika, 52, 333-343

Sedivy, J. A., Rienks, S., Leake, R., \& He, A. S. (2020). Expanding our understanding of the role of peer support in child welfare workforce retention. Journal of Public Child Welfare, 14, 80-100. https://doi.org/10.1080/15548732.2019.1658020

Smith, B. D. (2005). Job retention in child welfare: Effects of perceived organizational support, supervisor support, and intrinsic job value. Children and Youth Services Review, 27, 153-169

Tai, T. W. C., \& Robinson, C. D. (1998). Reducing staff turnover: A case study of dialysis facilities. Health Care Management Review, 23(4), 21-42

Travis, D. J., Lizano, E. L., \& Mor Barak, M. E. (2016). 'I'm so stressed!': A longitudinal model of stress, burnout and engagement among social workers in child welfare settings. The British Journal of Social Work, 46, 1076-1095

Trzesniewski, K. H., Donnellan, M. B., \& Robins, R. W. (2003). Stability of self-esteem across the life span. Journal of Personality and Social Psychology, 84, 205-220

Tuominen-Soini, H., \& Salmela-Aro, K. (2014). Schoolwork engagement and burnout among Finnish high school students and young adults: Profiles, progressions, and educational outcomes. Developmental Psychology, 50, 649-662. https://doi.org/10.1037/a0033 898

US Department of Health and Human Services (US DHHS). (2020). Child and family services reviews aggregate report: Round 3: FYs 2015-2018. Author. Retrieved from https://www.acf. hhs.gov/cb/report/child-and-family-services-reviews-aggre gate-report-round-3-fiscal-years-2015-2018

Vermunt, J. K. (2010). Latent class modeling with covariates: Two improved three-step approaches. Political Analysis, 18, 450-469

Vermunt, J. K., \& Magidson, J. (2002). Latent class cluster analysis. In J. Hagenaars, \& A. McCutcheon (Eds.), Applied latent class analysis. (pp. 89-106). Cambridge University Press.

Wilke, D. J., Radey, M., King, E., Spinelli, C., Rakes, S., \& Nolan, C. R. (2018). A multi-level conceptual model to examine child welfare worker turnover and retention decisions. Journal of Public Child Welfare, 12, 204-231

Wilke, D. J., Radey, M., \& Langenderfer-Magruder, L. (2017). Recruitment and retention of child welfare workers in longitudinal research: Successful strategies from the Florida Study of Professionals for Safe Families. Children and Youth Services Review, $78,122-128$ 
Wilke, D. J., Rakes, S., \& Randolph, K. A. (2019). Predictors of early departure among recently hired child welfare workers. Social Work, 64, 188-197

Zeitlin, W., Augsberger, A., Auerbach, C., \& McGowan, B. (2014). A mixed-methods study of the impact of organizational culture on workforce retention in child welfare. Children and Youth Services Review, 38, 36-43. https://doi.org/10.1016/j.childyouth.2014.01. 004
Publisher's Note Springer Nature remains neutral with regard to jurisdictional claims in published maps and institutional affiliations. 